Wiegers, T.A.

General practitioners and their role in maternity care.

Health Policy: 66, 2003, nr. 1, p. 51-59

\begin{tabular}{|l|l|}
\hline Postprint Version & 1.0 \\
\hline Journal website & $\underline{\text { http://dx.doi.org }}$ \\
Pubmed link & $\begin{array}{l}\text { http://www.ncbi.nlm.nih.gov/entrez/query.fcgi?cmd=Retrieve\&db=pubmed\&dop } \\
\text { t=Abstract\&list uids=14499165\&query hl=15\&itool=pubmed docsum }\end{array}$ \\
\hline DOI & $\underline{10.1016 / \text { S0168-8510(03)00025-3 }}$
\end{tabular}

E-mail address: t.wiegers@nivel.nl (T.A. Wiegers).

\title{
General practitioners and their role in maternity care
}

\author{
T.A. WIEGERS \\ Nivel (National Institute for Health Services Research), P.O. Box 1568, 3500 BN Utrecht, The \\ Netherlands
}

\begin{abstract}
During the last century the perception of pregnancy and childbirth has changed from a normal, physiological lifeevent to a potentially dangerous condition. Maternity care has become more and more obstetrical care, focussed on pathology and complications. The involvement of general practitioners (GPs) in maternity care is strongly reduced and almost everywhere the same reasons are found: interference with lifestyle and interruption of office routine, fear of litigation and costs of malpractice insurance, insufficient training and insufficient numbers of cases to retain competency. In Canada, the USA, and to a lesser extent in Australia and New Zealand, GPs still providing intrapartum care are GPobstetricians rather than maternity care providers. They provide low-risk as well as highrisk obstetrical care, especially in rural areas with few specialist obstetricians. In Europe, GPs do not provide high-risk obstetrical care. Instead they emphasize their role as generalist, and compete with midwives for a central role in maternity care for women with an uncomplicated pregnancy. The ongoing medicalisation of childbirth and the changing attitudes towards the demands of maternity care practice have diminished the role of GPs or family physicians. If they want to stay involved in maternity care in the future they need to cooperate with midwives, preferably in shared care programs.
\end{abstract}

\section{INTRODUCTION}

Maternity care is care for the well-being of women and newborn during pregnancy, childbirth and the first weeks or months after the baby is born. Maternity care is prevention, preparation, education and support, and, if necessary, intervention. There is general agreement that for any given outcome of pregnancy, such as the condition of mother and newborn, this outcome should be achieved with a minimum of interference with natural processes and the woman's autonomy [1]. Therefore, midwives and general practitioners (GPs) or family physicians, as primary care providers, with their focus on the physiology of pregnancy and childbirth, are the professionals of first choice to provide maternity care for women at low risk of complications. Obstetricians, with their focus on the pathology of pregnancy and childbirth, are specialised in the care for women with obstetrical risks or complications that may lead to adverse outcomes for them or their baby. But almost everywhere in the developed world, as the place of birth shifted from home to hospital, specialist obstetricians, except in remote rural areas, took over responsibility, not only for complicated births but for normal childbirth as well. The role of midwives was reduced to that of obstetrical nurses in hospitals (Europe) or midwives were banned altogether (North America). Furthermore, with the growing knowledge in reproductive medicine and the rapid development of medical technology the emphasis in care for pregnant women has shifted 
from physiology, psycho-social aspects of preparation and support to pathology, to medical or obstetrical aspects of risk assessment, prenatal testing, treatment of pathological conditions, and interventions during childbirth. This process is known as the 'medicalisation' of childbirth. GPs have contributed to this development, by leaving maternity care to the obstetricians or becoming GPobstetricians themselves. This process of medicalisation has led to the rise of cesarean section rates as well as overall intervention rates to unacceptable heights. Unacceptable, because no direct relation with perinatal or maternal morbidity and mortality rates have been found [2]. According to the World Health Organisation (WHO) cesarean section rates should range from about $5 \%$ to a maximum of $15 \%$ [3], but in many developed countries the average is much higher (Germany, 18.9\%; Canada, 20.5\%; USA, 22\%) [4]. The only way to stop this process of ongoing medicalisation is to realize that pregnancy and childbirth are essentially physiological events, that need no medical intervention unless in specific circumstances, and to act accordingly. The question is whether 'demedicalisation' is possible. For instance, should GPs try to regain their position in caring for normal childbirth and will that help to reduce further medicalisation? Or should a different system of maternity care be developed? For instance, should midwives be encouraged to (re)take responsibility for normal childbirth? In this paper I want to focus on the role of GPs in maternity care in North America, Northern Europe, Australia and New Zealand, by finding an answer to the following questions:

what is the involvement of GPs in maternity care and what has been their involvement over the years;

what tasks do GPs perform in relation to maternity care; what are GPs opinions on their (future) role in maternity care.

\section{METHOD}

To find an answer to the questions about the present and future role of GPs in maternity care a literature search was performed in Medline for the period 1994-2000, with the following requests: (1) 'Physicians-Family'; (2) 'Family-Practice’; (3) 'Primary- Health-Care’; (4) general; (5) medicine; (6) general medicine; (7) family; (8) medicine; (9) family medicine; (10) \#1 or \#2 or \#3 or \#6 or \#9; (11) 'Prenatal-Care'; (12) 'Perinatal-Care'; (13) ‘Obstetrics'; (14) 'Obstetrics-and-GynecologyDepartment- Hospital’; (15) 'Hospitals-Maternity'; (16) \#11 or \#12 or \#13 or \#14 or \#15; (17) antenatal; (18) care; (19) antenatal care; (20) natal; (21) care; (22) natal care; (23) maternity; (24) care; (25) maternity care; (26) maternity; (27) services; (28) maternity services; (29) obstetric; (30) care; (31) obstetric care; (32) \#19 or \#22 or \#25 or \#28 or \#31; (33) \#16 or \#32; (34) \#10 and \#33.

This was followed by an additional search in PubMed for the years 2001 and 2002, with the following requests: (1) 'Physicians-Family'; (2) 'Family-Practice'; (3) 'Primary- Health-Care'; (4) general medicine; (5) family medicine; (6) \#1 OR \#2 OR \#3 OR \#4 OR \#5; (7) 'Prenatal-Care’; (8) 'Perinatal-Care'; (9) 'Obstetrics'; (10) 'Obstetricsand- Gynecology-Department-Hospital'; (11) 'Hospitals-Maternity’; (12) \#7 OR \#8 OR \#9 OR \#10 OR \#11; (13) \#6 AND \#12; (14) antenatal care; (15) natal care; (16) maternity care; (17) maternity services; (18) obstetric care; (19) \#14 OR \#15 OR \#16 OR \#17 OR \#18; (20) \#12 OR \#19; (21) \#6 AND \#20.

A total of 602 records were found, relating to journal articles, editorials, comments and letters.

Of these 102 were selected for further study on the basis of their title and/or abstract. The information was sorted according to geographical region. Much information was found about Canada (25), the US (39) and the UK (20), considerably less about other European countries (5), or about Australia and New Zealand (13). Additional available data about the Netherlands (2) and Dutch-language data about Europe (2), not from the Medline- or PubMed-search, were included in this review.

\section{RESULTS}

\subsection{North America}

In Canada maternity care has long been the sole responsibility of physicians and nurses, because there hardly were any midwives and their practice was neither legal nor officially recognised. Family physicians in Canada can manage low-risk as well as non-low-risk cases, but they are expected to 
adhere to guidelines for specialist consultation [5]. Since 1993 licensed midwives have been introduced in some Canadian provinces, but their numbers are only slowly growing.

From 1975-1976 to 1984-1985 the proportion of women giving birth assisted by a family physician fell from 61 to 55\% of all women giving birth in Canada [6]. In 1983, across Canada, a majority of family physicians, $68 \%$, still attended births, but this rapidly decreased to $46 \%$ in 1988 [7] and $19 \%$ in 1997-1998 [8]. The top four reasons given to indicate this change in practice were lifestyle issues (47.5\%), concern about medicolegal liability (26.5\%), insufficient numbers of cases per year (23.1\%) and inadequate compensation (21.4\%) [9]. Not only an increasing number of family physicians stop providing intrapartum care (i.e., care during birth), but an increasing number of residents choose not to start providing intrapartum care. A survey in 1992 among graduates from the family medicine residency program during the period 1987-1991 revealed that the most frequently cited reasons not to do deliveries were interference with lifestyle (83\%), interruption of regular office routine (62\%), insufficient training in obstetrics (39\%) and cost of malpractice insurance and fear of litigation (36\%) [10]. An average of $44 \%$ of family medicine residents, on entry of the residents program in the years 1991-1994, intended to practice obstetrics after graduation. By graduation 2 years later, however, only $34 \%$ were planning to practice obstetrics [11]. Factors that influenced their decision about practising obstetrics, and were rated significantly different at entry and exit of the residency program, were in the areas of lifestyle, adequacy of compensation and desire to participate in a happy family event [11].

In April 1995, an editorial in the Canadian Family Physician stated that: 'Obstetrical care in general, but family practice obstetrics in particular, is today at a critical point in its evolution. Although midwifery is now a legally mandated profession, the number of registered midwives will increase only slowly. Obstetric specialists, especially those in regional and community hospitals, are greatly overworked, aging as a specialty, and diminishing in numbers. . . Small-hospital obstetrics is in jeopardy because specialist support is unavailable and family practice obstetricians are reducing in numbers.' [12].

To prevent further reduction of the number of family physicians practising obstetrics and to improve working conditions for family physicians who practice obstetrics, several solutions have been proposed. One of them is 'shared-call obstetric groups', where each practitioner in turn takes a 24-h call shift to cover the group's deliveries. Antenatal and postnatal care is provided by each practitioner during office hours for their own patients [13]. This greatly reduces the interference with lifestyle and the interruption of regular office routines for physicians practising obstetrics. It implies, however, that all physicians in a shared-call group are prepared to provide intrapartum care, even if only a few of them provide ante- and postnatal care. Besides, this is not a solution for insufficient training, insufficient numbers of births and inadequate financial compensation.

Overall it is estimated that $12-15 \%$ of all births in the USA are attended by family physicians [14]. In 1978, 46\% of family physicians and in 1992 only $24 \%$ of family physicians included obstetrics in their practices [14]. In 1993, this downward trend seemed to be reversed, with $26 \%$ of the active members of the American Academy of Family Physicians (AAFP) listed as including routine obstetric care in their hospital practices [15]. In 1994, 31\% of all members of the AAFP included obstetrics as part of their practice [14]. The 1996 data however show a return to the downward trend: nationwide in the US 25\% of family physicians were involved in maternity care in 1996 [16].

Family physicians providing obstetrical care can have different hospital privileges for different obstetrical procedures, ranging from 'no consultation required' via 'hospital required consultation' to 'mandatory transfer to consultant' [17]. For instance, in 1991 all family physicians who included obstetric care in their practice could assist in normal vaginal delivery without consultation, but in case of a vaginal delivery after cesarean $28 \%$ of family physicians required consultation and an additional $8 \%$ required transfer to a consultant. And in the case of a cesarean 23\% required consultation and 52\% required transfer. In rural areas, family physicians are less restricted than in urban settings, for instance, $41 \%$ of rural practitioners required no consultation or transfer for cesarean section, compared to $37 \%$ of suburban and $13 \%$ of metropolitan practitioners. The variations in restrictions per region and practice location cannot be explained by the degree of training of the family physicians, but it was found that larger hospitals are more restrictive than small or rural hospitals [17].

In 1993, 26\% of all family physicians included routine obstetric care in their hospital practices, $13 \%$ included complicated delivery in their hospital practices and 5\% performed cesarean sections. Physicians in rural settings were nearly twice as likely to have routine obstetric privileges, compared 
with family physicians in urban areas (39\% compared with 21\%). Similarly, $25 \%$ of family physicians in rural areas included complicated obstetric delivery compared with only $8 \%$ in urban settings. Cesarean sections were performed by $12 \%$ of rural family physicians, but only by less than $2 \%$ of urban family physicians [15].

Family physicians in favour of providing maternity care underscore their unique, familycentred approach, their relatively low intervention rates, compared to specialist obstetricians, and their outstanding outcomes, similar to midwives, as well as their lower costs, compared to other physicians [14]. And for those family physicians who choose not to provide intrapartum care at least involvement in prenatal and postpartum care in the form of shared care is promoted. According to Larimore no more than $25 \%$ of family physicians are providing shared care, most often shared with obstetricians [18].

Collaboration with midwives is still rare. Although midwifery care has never really been gone from the US, it has been marginalised and midwives are only slowly regaining their position as independent practitioner, inside as well as outside hospital. In 1970, the percentage of midwife attended births was less than 0.5 but in 1997 that was increased to 7.0 percent of all births in the US [19].

\subsection{Europe}

In a survey among GPs in Europe in 1993/1994 about the role of general practice in Primary Health Care one of the questions was: 'Are you involved in the following activities: intrapartum care; routine antenatal care; immunization programme for children; paediatric surveillance for children under 4; family planning/contraception; homeopathic medicine?' [20]. In the 12 countries of the European Union at that time on average $66 \%$ of respondents indicated that they were involved in antenatal care, while only $15 \%$ were involved in intrapartum care. Antenatal care appeared to be an integral part of a GPs workload in Ireland, Denmark, the UK, and Portugal, with more than $90 \%$ of respondents indicating their involvement in antenatal care (Table 1). Intrapartum care is seldom provided by GPs in Europe. Only in the UK more than 30\% of GPs indicated their involvement in intrapartum care in the early 1990s. In France, Portugal, Spain, Italy, and Luxembourg less than 10\% of GPs were involved in intrapartum care (Boerma, unpublished data).

\section{[ TABLE 1 ]}

The Scandinavian countries and the Netherlands have a tradition of perceiving birth above all as a normal physiological process and of valuing low intervention rates [21]. GPs in these countries are primary caregivers and gatekeepers for specialist care. In Norway, antenatal care is usually provided by community GPs and most pregnant women will go to hospital and to secondary care when labour starts [22]. There most births will be assisted by midwives, under supervision of an obstetrician [23]. In Denmark, the provision of antenatal care is shared between general practice, centres for midwifery, and hospital departments. The recommended schedule of antenatal visits reflects the role of the GP as gatekeeper and includes three visits to the GP, a minimum of five visits to a midwife, and one visit to a hospital department [24]. To give birth most women go to hospital where they are assisted by midwives, who will consult or refer to an obstetrician in case of complications [23].

In the Netherlands in 1965 more than two-thirds of all births took place at home and the GPs were involved in more than half of those births, while the other home births were assisted by midwives [25]. Women gave birth in hospital only after referral to a gynaecologist. To stop or slow down the increasing referral rate occurring during the 1960s and 1970s, pregnant women at low risk of complications were given the choice to give birth in hospital, assisted by their own midwife or GP. It did not slow down the referral rate, however. Instead it led to a further reduction of the home birth rate. In 1998, only $29 \%$ of all births took place at home, almost all assisted by midwives. GPs were the primary caregiver in less than $5 \%$ of all births and were involved in no more than $10 \%$ of all home births [26]. Sixty percent of all births in 1998 took place under supervision of a gynaecologist, because of existing pathology or increased risk of complications.

Not only the number of births a GP attends is reduced, also the number of GPs attending births is reduced: in the early 1980s approximately 40 percent of all GPs still assisted in childbirth, in 1990 that was reduced to 26 percent, while in 1998 only 16 percent of all GPs provided care during birth. And while in 1991 more than $60 \%$ of GPs held the opinion that intrapartum care was an integral part of 
their job, in 1999 only a minority agreed to that statement: 45\% of those established and 34\% of those starting as GP [27]. Most frequently mentioned reasons for GPs to stop providing care during birth were: insufficient numbers of cases to retain competency (18\%), establishment of a midwifery practice in the neighbourhood (15\%), interruption of regular practice routine and increased workload (13\%) and difficulty finding a locum tenens or successor who is prepared and able to provide intrapartum care (8\%) [27]. The reduced involvement of GPs in maternity care is accompanied by a relatively small increase in the involvement of midwives, but a large increase in that of gynaecologists, thereby illustrating the increased medicalisation of childbirth over the years.

In the UK, GPs can provide maternity care at home, in free standing GP maternity units or in integrated general maternity units. A 6-month hospital obstetric post (usually combined with gynaecology) as part of the 2-year hospital-based vocational training of GP registrars is normally a requirement to join the obstetric list and become a GP obstetrician [28]. A 1992 national survey of UK GPs found that about 31\% claimed to provide labour care and $90 \%$ antenatal and postnatal care; while 27 and 95\% of GPs, respectively, stated that they wished to provide such care in the future. It is estimated, however, that no more than $10-15 \%$ of GPs actually still provide labour care in hospital and/or at home, perform labour procedures (e.g. forceps) and provide continuity of care throughout pregnancy and the postnatal period [29]. The number of births assisted by GPs has declined markedly: in 1965 about 50\% of all births took place under a GPs care, in 1994 that was less than $0.2 \%$. The reasons for GPs to reduce their involvement in labour care are found to be: perceived lack of experience, fear of litigation, changes in the organisation of out of hours cover, unacceptable encroachment on off duty hours and inadequate remuneration [30]. It has become normal practice for pregnant women to be booked for delivery under the care of a consultant obstetrician, although most of the intrapartum care will be provided by hospital midwives. Antenatal care is usually provided by the hospital team or as 'shared care' by the hospital team and a community midwife or GP.

Since the Cumberlege Report 'Changing Childbirth' (Department of Health 1993) different patterns of providing maternity services have been developed, such as community-led maternity care, midwifery group practices and team midwifery. In many of these schemes the role of GPs is reduced to booking the women for delivery, backup for midwives and maybe a few antenatal checks. However, this has led to concern regarding the interprofessional cooperation between GPs and midwives. Research found that several GPs felt marginalised or unsure of their role, especially when women went exclusively to midwife clinics [31]. In another study GPs feared to be excluded from the routine antenatal care of their patients by the development of midwifery group practices [32].

\subsection{Australia and New Zealand}

In Australia, there is much debate about whose role it should be to provide routine antenatal care: the GP, the midwife or the obstetrician. In 1989, a ministerial task force in New South Wales identified that the system was 'failing to effectively use the skills of GPs and midwives in the care of women who have low to moderate risk factors in their pregnancy' [33]. The recommendations included an increase in shared care arrangements and the introduction of midwifery clinics and independent midwives to provide antenatal care. Shared antenatal care programs have since been set up by many maternity hospitals in conjunction with local GPs and sometimes community midwives, but satisfaction with current shared care programs is found to be low. A shared care arrangement means that a pregnant woman will see a specialist obstetrician at her first visit at 12-14 weeks gestation. If complications do not develop a family physician or a midwife or physician team will provide the remainder of the pregnancy care, with the exception of two or more visits to the specialist obstetrician at the 28th and 36th week of pregnancy [34]. Intrapartum care is provided by midwives, obstetricians and GPs. In 1989, in Victoria 11\% of births were attended by GPs, $43 \%$ were attended by private obstetricians and $45 \%$ by public hospital midwives and doctors. Especially in metropolitan areas the number of GPs providing intrapartum care continues to decline. The reasons are: low remuneration and high insurance premiums, but also the unpredictable working hours, difficulty of finding a suitable locum to provide cover for holidays, difficulty of maintaining obstetrics skills and fear of litigation [35].

In 1993/1994, approximately 62\% of GPs in rural and remote areas in Australia practised obstetrics. The majority of them, $83 \%$ had completed some formal postgraduate training in obstetrics, including performing Caesarean sections and using forceps and ventouse [36]. As in many other countries, the 
number of GPs providing intrapartum care declined significantly, with rising indemnity insurance, lifestyle issues and poor remuneration being the most important reasons for ceasing obstetrics [37]. In New Zealand, legislative changes in 1990 established independent midwifery within the health care system. Between 1990 and 1996, GP involvement in maternity care still accounted for at least $50 \%$ of deliveries, but since then decreased rapidly and almost completely disappeared [38]. In less than no time midwives established themselves as preferred care giver during pregnancy and birth. Today $70 \%$ of all pregnant women in New Zealand have a midwife as their lead maternity carer [39]. Only in rural areas are GPs still involved in maternity care. A study among 338 rural GPs in November 1999 found that 21\% of them still provided intrapartum obstetric care [40].

\section{CONCLUSION}

This short overview of the role of GPs and family physicians in maternity care in a number of developed countries shows several things. First of all it shows that the role of GPs in maternity care, especially in intrapartum care, is diminishing and almost the same reasons are found everywhere: interference with lifestyle and interruption of office routine, fear of litigation and costs of malpractice insurance, insufficient training and insufficient numbers of cases to retain competency. Secondly, it shows that GPs providing care during pregnancy and childbirth are often GP-obstetricians. They provide obstetrical care for women with low-risk as well as high-risk pregnancies, often because and as long as there are not enough specialist obstetricians available, for instance in remote rural areas. Thirdly, it shows that GPs who provide maternity care, emphasizing their primary care or 'familycentred' approach aimed at women with low-risk pregnancies, are in competition with midwives.

This means GPs are always caught between obstetricians on the one hand and midwives on the other. They compete with obstetricians on the point of outcome by claiming that, with comparable populations, their intervention rates are lower [14, 41, 42]. They compete with midwives on the point of continuity of care by claiming they provide real continuity of care because midwives usually have no previous knowledge of the woman and her family and do not provide ongoing care to the newborn child [43]. Larimore and Reynolds are strong advocates of family physicians' involvement in maternity care and to promote that they state that ' . . family physicians should restore their commitment to the person-centred delivery of childbirth care, for the sake of the women of today and the children of tomorrow.' [43].

In 2000, in Fortaleza, Brazil, a conference was held, called: 'The International Conference on Humanization of Childbirth' [44]. There Marsden Wagner, former regional officer for women's and children's health of the WHO regional office for Europe, argued that having primary maternity care in the hands of midwives is a central strategy in the humanization of birth. First of all, because research has shown that for low-risk women primary care provided by midwives is as safe or safer than care provided by physicians. Secondly, because scientific evidence shows that, compared with physicianattended low-risk birth, midwifeattended birth has significantly lower rates of unnecessary invasive interventions. Thirdly, because midwifery care is cost saving and finally, because midwifery care is statistically significantly more satisfying to the woman and her family [2]. In studies comparing care provided by midwives and care provided by physicians, the physicians usually are obstetricians.

To 'humanize birth' and to shift the balance back from obstetrical care to maternity care for the majority of pregnant women reintroduction of care providers with a primary care and personcentred focus is needed. These can be GPs as well as midwives, provided that GPs assume a 'midwifery- like' approach. While many GPs are reluctant to start or to continue providing maternity care, especially intrapartum care, a growing number of midwives is providing maternity care throughout pregnancy, childbirth and the postpartum period. If GPs want to ensure their future involvement in maternity care, they should focus on cooperation instead of competition with midwives, and further develop shared care programs to provide person-centred, low-interventionist care for women with low-risk pregnancies. Close cooperation between different care providers and recognition of each other's competence and limitations is essential to ensure good quality maternity care for all women. 
Wiegers, T.A.

General practitioners and their role in maternity care.

Health Policy: 66, 2003, nr. 1, p. 51-59

TABLES

Table 1

GPs involvement in antenatal and intrapartum care in countries of the European Union in 1993-1994

\begin{tabular}{llll}
\hline & Number of respondents & \multicolumn{2}{c}{ Estimated percentage of GPs involved in } \\
\cline { 3 - 4 } & & Antenatal care (\%) & Intrapartum care $(\%)$ \\
\hline UK & 294 & $>90$ & $20-40$ \\
Denmark & 197 & $>90$ & $20-40$ \\
Ireland & 130 & $>90$ & $10-20$ \\
Portugal & 149 & $>90$ & $5-10$ \\
Belgium & 496 & $60-90$ & $20-40$ \\
France & 233 & $60-90$ & $5-10$ \\
Italy & 242 & $60-90$ & $<5$ \\
The Netherlands & 202 & $40-60$ & $20-40$ \\
Greece & 114 & $20-40$ & $10-20$ \\
Spain & 466 & $20-40$ & $<5$ \\
Luxembourg & 52 & $20-40$ & $<5$ \\
Germany & 153 & $<20$ & $10-20$ \\
\hline
\end{tabular}

Source: Nivel/European Survey of the task profiles of GPs (unpublished data).

\section{REFERENCES}

[1] Enkin M, Keirse MJNC, Renfrew M, Neilson JA. Guide to Effective Care in Pregnancy and Childbirth. Oxford: Oxford University Press, 1995:389.

[2] Wagner M. Fish can't see water: the need to humanize birth. International Journal of Gynaecology and Obstetrics 2001;75:S25-37.

[3] Chalmers B, Mangiaterra V, Porter R. WHO principles of perinatal care: the essential antenatal, perinatal, and postpartum care course. Birth 2001;28:202-7.

[4] DeClerq E, Viisainen K. The politics of numbers: the promise and frustration of cross-national analysis. In: DeVries R, Wrede S, van Teijlingen E, Benoit C, editors. Birth by Design: Pregnancy, Maternity Care and Midwifery in North America and Europe. New York, London: Routledge, 2001:267-79.

[5] Reid AJ, Carrol JC, Ruderman J, Murray M. Consultation in family practice obstetrics. Canadian Family Physician 1995;41:591-8.

[6] Smith LFP, Reynolds JL. Factors associated with the decision of family physicians to provide intrapartum care. Canadian Medical Association Journal 1995;152(11):1789-97.

[7] Kaczorowski J, Levitt C. Intrapartum care by general practitioners and family physicians. Canadian Family Physician 2000;46:587-96.

[8] Reid AJ, Grava-Gubins I, Carroll JC. Family physicians in maternity care. Still in the game? Canadian Family Physician 2000;46:601-11.

[9] Woodward CA, Rosser W. Effect of medicolegal liability on patterns of general and family practice in Canada. Canadian Medical Association Journal 1989;141:291-9.

[10] Buckle D. Obstetrical practice after a family medicine residency. Canadian Family Physician 1994;40:261-8.

[11] Ruderman J, Holzapfel SG, Caroll JC, Cummings S. Obstetrics anyone? How family medicine residents' interests changed. Canadian Family Physician 1999;45:638-47.

[12] Chance G. Family practice obstetrics. Time of opportunity. Canadian Family Physician 1995;41:548-9.

[13] Shapiro JL. Satisfaction with obstetric care. Patient survey in a family practice shared-call group. Canadian Family Physician 1999;45:651-7.

[14] Long R. Obstetrics in family practice. Medicine and Health 2000;83:15-8.

[15] Kahn NB, Schmittling G. Obstetric privileges for family physicians: a national study. Journal of American Board for Family Practice 1995;8:120 -7.

[16] Sinusas K. Deliveries by Family Physicians in Connecticut. Archives of Family Medicine 2000;9:434-8.

[17] Wadland WC, Havron AF, Garr D, Schneeweiss R, Smith M. National survey on hospital-based privileges in family practice obstetrics. Archives of Family Medicine 1994;3:793 -800.

[18] Larimore W. Shared antenatal care: an improved paradigm for women's health care. Journal of Family Practice 1998;46:31 -3. 
[19] DeVries R. Midwifery in the Netherlands: vestige or vanguard? Medical Anthropology 2001;20:277-311.

[20] Boerma WGW, Fleming DM. The role of general practice in Primary Health Care. WHO regional office for Europe 1998.

[21] Johanson R, Newburn M, Macfarlane A. Has the medicalisation of childbirth gone too far? British Medical Journal 2002;324:892-5.

[22] Backe B, Jacobsen G. General practitioners' compliance with guidelines for antenatal care. Scandinavian Journal of Primary Health Care 1994;12:100-5.

[23] Wieman F, de Leeuw AK, Hingstman L, Berghs G. Verloskundige zorg in een aantal Europese landen: een inventarisatie, Utrecht, Nivel 1991

[24] Kristensen FB, Andersen KV, Andersen AMN, Hermann N, Knudsen VW, Nielsen HK. Physical examinations and laboratory tests in antenatal care visits in Denmark. Scandinavian Journal of Primary Health Care 1995;13:52 -8.

[25] Campos Cardoso A. de Geborenen naar aard van verloskundige hulp en plaats van geboorte 1982 (Births by obstetric assistance and place of delivery 1982). Mndber gezondheid (CBS) 1983/12: 48-59.

[26] Offerhaus PM, Anthony S, Pal-de Bruin KM van der, Buitendijk SE. De thuisbevalling in Nederland. Rapportage 1995-1998. Leiden, TNO-Preventie en Gezondheid 2000.

[27] Wiegers T, Hingstman L. Inventarisatie 'verloskundig actieve huisartsen'. Utrecht, Nivel 1999.

[28] RCGP Maternity Care Group. The role of general practice in maternity care. Occassional Paper (Royal College of General Practice) 1995;72:1-14.

[29] Smith LFP. Should general practitioners have any role in maternity care in the future? British Journal of General Practice 1996;46:243-7.

[30] Zander L, Chamberlain G. ABC of labour care. Place of birth. British Medical Journal 1999;318:721-3.

[31] Fleissig A, Kroll D, McCarthy M. General practitioners' views in the implementation of communityled maternity care in South Camden, London. British Journal of General Practice 1997;47:45-6.

[32] Fenwick N, Morgan M, McKenzie C, Wolfe C. General practitioners' attitudes to the development of midwifery group practices. British Journal of General Practice 1998;48:1395-8.

[33] Haertsch M, Campbell E, Sanson-Fisher R. Who can provide antenatal care? The views of obstetricians and midwives. Australian and New Zealand Journal of Public Health 1998;22:471-5.

[34] Laslett AML, Brown S, Lumley J. Women's views of different models of antenatal care in Victoria, Australia. Birth 1997;24:81 -9.

[35] Gunn J, Lumley J, Young D. Involvement of Victorian general practitioners in obstetric and postnatal care. Australian Family Physician 1998;27:S78-83.

[36] Welch R, Power R. General practitioner obstetric practice in rural and remote Western Australia. Australian and New Zealand Journal of Obstetrics and Gynaecology 1995;35:241-4.

[37] Watts RW, Marley JE, Beilby JJ, MacKinnon RPG, Doughty S. Training, skills and approach to high-risk obstetrics in rural GP obstetricians. Australian and New Zealand Journal of Obstetrics anc Gynaecology 1997;37:424-6.

[38] Ferguson W. The decline of general practitioner involvement in maternity care and its possible consequences for maternal and infant health. New Zealand Medical Journal 1999;112:410-1.

[39] New Zealand College of Midwives-midwifery information (2002) http://www.midwife.org.nz [40] Janes R, Dowell A, Cormack D. New Zealand rural general practitioners 1999 survey-part 1: an overview of the rural doctor workforce and their concerns. New Zealand Medical Journal 2001;114:492-5.

[41] Deutschman ME, Sills DA, Connor PD. Perinatal outcomes: a comparison between family physicians and obstetricians. J Am Board Fam Pract 1995;8:440-7.

[42] Hueston WJ, Lewis-Stevenson S. Provider distribution and variations in statewide cesarean section rates. Journal of Community Health 2001;26(1):1-10.

[43] Larimore WL, Reynolds JL. Family practice maternity care in America: ruminations on reproducing an endangered species-family physicians who deliver babies. J Am Board Fam Pract 1994;7:478-88.

[44] Fau'ndes A. (Guest Editor) International Conference on Humanization of Childbirth. 2-4 November 2000, Fortaleza, Brazil. International Journal of Gynaecology and Obstetrics, 2001; 75 (Suppl 1). 